\title{
DIREITO COMO PRODUTO E PRODUTOR DE PRÁTICAS SOCIAIS: ANÁLISE A PARTIR DO PENSAMENTO DE PIERRE BOURDIEU
}

\author{
Roberto Leonardo da Silva Ramos ${ }^{1}$ \\ Luciano da Silva ${ }^{2}$
}

\section{Resumo}

O texto refletiu se o direito é produto ou produtor de práticas sociais, tendo como hipótese que a dinâmica relacional é influenciada e influencia o campo jurídico. Adotou-se o método de abordagem dedutivo com referência no estruturalismo, levando em conta dados teóricos preestabelecidos essenciais ao desfecho, ainda considera a análise da estrutura e a relação entre seus elementos e destes com o todo. Discorreu-se acerca das categorias campo, capital e habitus, desenvolvidas por Pierre Bourdieu, para entender a dinâmica relacional do campo jurídico e as disputas determinantes das regras de comportamento.

Palavras-chave: Pierre Bourdieu; Dinâmica; Campo jurídico; Prática social; Influência.

\section{THE RIGHT AS A PRODUCT AND PRODUCER OF SOCIAL PRACTICES: ANALYSIS FROM PIERRE BOURDIEU'S THOUGHT}

\begin{abstract}
This work reflects on whether the right is a product or producer of social practices considering the hypotheses of relational dynamic is influenced and also influences the legal field. The deductive approach has been adopted in reference to structuralism considering an essential pre-established theoretical data to obtain the outcome. It also considers the structure's analysis and the relation among its elements and between them and the whole. The categories developed by Pierre Bourdieu has been discussed: field, capital, and habitus in order to understand the relational dynamic of the legal field and the disputes that determine the rules of behavior.
\end{abstract}

Keywords: Pierre Bourdieu; Dynamic; Legal field; Social practices; Influence.

\section{1 - Introdução}

O ser humano vive em busca de satisfazer suas necessidades e, não dificilmente, os interesses de um coincidem com o do outro, dada a escassez dos bens da vida pretendidos. Esse problema fático aumenta quando se considera a colisão de interesses em relação a

\footnotetext{
${ }^{1}$ Professor da Universidade Federal do Sul e Sudeste do Pará (UNIFESSPA), Faculdade de Direito (FADIR). Doutor e Mestre em Ciências Jurídicas pela Universidade Federal da Paraíba (UFPB), Especialista em Direito Público pela Universidade Cândido Mendes/RJ. Graduado em direito pelo Centro Universitário de João Pessoa (UNIPÊ). Líder do Grupo de Pesquisa Direito e Sociedade. Endereço eletrônico: robertoleonardo@mouraramos.com.br. Endereço profissional: Folha 31, Quadra 7, Lote 100 - Especial, S/N UNIFESSPA Campus I, Faculdade de Direito (FADIR), Instituto de Estudos em Direito e Socidade (IEDS), Bairro: Nova Marabá, CEP: 68.507-590, Marabá/Pará.

${ }^{2}$ Doutor em Filosofia (UFPB-UFRN-UFPE), Professor de filosofia (UFCG). Professor da Universidade Federal de Campina Grande, Centro de Humanidades, Unidade Acadêmica de Ciências Sociais, Área de Filosofia. Rua Aprígio Veloso - de 748. 58429140 - Campina Grande, PB - Brasil Telefone: (83) 21011211
} 
coletividades de pessoas, implicando em disputas sociais. Apesar desta realidade, o convívio harmônico é necessário ao desenvolvimento social, sendo atribuído ao direito o múnus de controle necessário ao estabelecimento de padrões comportamentais úteis a estabilização da sociedade.

Essa função tradicional do direito é questionada no presente capítulo nos seguintes termos: O direito é produto ou produtor de práticas sociais? Parte-se da hipótese de que a dinâmica relacional é influenciada e também influencia o direito, este que precipuamente oculta as tensões sociais com o pretexto de pacificação. Adota-se o método de abordagem dedutivo com referência no estruturalismo, haja vista o texto partir de dados teóricos predeterminados e necessários à busca da resposta final, ademais a análise considera uma estrutura e a relação entre seus elementos e destes com o todo.

Nesse ínterim, o capítulo fundamenta-se em categorias desenvolvidas pelo sociólogo Pierre Bourdieu, discorrendo acerca do campo, capital, habitus e relacionando-os com a prática social. Campo é o espaço social onde se dá as disputas entre os agentes para ocupar as posições mais privilegiadas e de maior influência, o que é alcançado com maior ou menor intensidade a depender do grau de acumulação do capital específico em disputa. Por sua vez, capital é o poder capaz de promover o deslocamento dos agentes dentro do campo. Já o habitus são estruturas mentais adquiras com a internalização de valores durante a trajetória do sujeito em um determinado campo. O habitus norteia o juízo de valor do agente, influenciando, portanto, em seus comportamentos, logo, as práticas sociais estruturam e são estruturadas pela disputa do capital no campo.

A partir das ideias acima, desenvolve-se acerca da dinâmica relacional do campo jurídico, expondo sobre as disputas internas que determinam as regras de comportamento influenciadoras na acumulação do capital almejado. A acomodação aos padrões de condutas direciona aos agentes de mais destaques no campo, estes, consequentemente, serão os reprodutores da cultura jurídica e estabelecerão as normas a serem seguidas pela sociedade. Neste contexto, segue-se o pensamento de Bourdieu para reafirmar a autonomia do campo jurídico para dizer qual o direito aplicável, ao tempo em que seus agentes por integrarem outros campos, também submetem o jurídico a influências externas.

Deste modo, o direito é responsável pela delimitação dos fatos que serão objeto de sua apreciação, denominados de fato jurídicos. O fato não jurídico corresponde a comportamentos de outros campos que não sujeitos à tutela do direito, mas podendo, em algum momento, 
estimular seu reconhecimento. Significa, então, afirmar que forças extrajurídicas possuem a potencialidade de interferir na produção do direito, cabendo a este, por meio do monopólio estatal, o reconhecimento oficial legitimado pela sociedade.

\section{2 - Campo, habitus, capital e a prática social}

Nesta seção, são tratadas as categorias analíticas abordadas pelo sociólogo Pierre Bourdieu, que tem como fio condutor em suas obras a relação entre o direito e as práticas sociais, ou seja, visa apresentar pressupostos ocultos que disciplinam a vida social e a função do direito nesse disciplinamento. Bourdieu (2001; 2004c) lança mão da sociologia como instrumento científico para se posicionar de modo crítico acerca de seus objetos abordados, sendo este o modo de identificar os pressupostos sociais de um objeto em análise e os pressupostos que originam o próprio objeto, que se dá através de tensões ideológicas.

Bourdieu destaca-se em superar tradicionais dicotomias da teoria social, como exemplo mais relevante a do subjetivismo e objetivismo. Nos termos dessa abordagem:

Se trata de escapar a la falsa alternativa entre una perspectiva objetivista (a La que conducen las explicaciones deterministas y mecânicas de La vida social) y una perspectiva subjetivista (que concibe las intenciones y La conciencia de los sujetos como explicación suficiente de La práctica) (INDA, 2001, p. 11).

Essa superação se dá pela conjugação do viés estruturalista e construtivista. Nas palavras de Inda (2001), o primeiro corresponde às estruturas objetivistas que orientam a prática social e, o segundo, a origem das estruturas psíquicas que condicionam e geram as práticas, havendo aproximação entre os antagonismos ao ponto de uma ser complementar a outra. Portanto, verifica-se a prática social como resultado não de um dado unilateral, mas, sim, de relações e conjugação das categorias desenvolvidas, que são o campo, capital e habitus.

Essa perspectiva de complementaridade mencionada acima é tratada de modo claro por Bourdieu (2004a, p. 149), ao se referir ao seu trabalho como construtivista estruturalismo ou estruturalista construtivismo, sendo estruturalismo (ou estruturalista) o que não está limitado aos sistemas simbólicos, mas também possui existência no mundo social, são estruturas que independem da vontade e consciência dos sujeitos e orientam suas práticas e 
representações. Em relação ao construtivismo ou construtivista, ele se refere à origem social do que denomina de habitus e estruturas sociais que denomina de campos, grupos e classes sociais, categorias analisadas a seguir dada a pertinência para entender as ideias do sociólogo francês. Campo, capital e habitus são categorias centrais do pensamento de Bourdieu, conforme enfatizado abaixo.

En síntesis, podemos decir que los conceptos clave em la teoria de Bourdieu son campo, habitus y capitales. El campo es esa estructura donde se da una lucha, de unos agentes que han interiorizado y asumido plenamente lãs reglas de juego-habitus- y donde hay unos capitales específicos, es decir um sistema de posiciones de poder para retener o expulsar a quienes no asumen sus códigos, o las reglas de su funcionamento (NAVARRO; DURÁN, 2012, p. 51).

A partir dos conceitos mencionados acima, segue análise detalhada de cada um. A categoria espaço social trazida por Bourdieu refere-se ao conjunto de relações invisíveis, que identificam a realidade social. Nos seus termos:

É possível, a esta altura da exposição, comparar o espaço social a um espaço geográfico no interior do qual se recortam regiões. Mas esse espaço é construído de tal maneira, que quanto mais próximo estiverem os grupos ou instituições ali situados, mais propriedades em comum eles terão. [...] as pessoas próximas no espaço social tendem a se encontrar próximas - por opção ou por força - no espaço geográfico [...] As interações, que proporcionam uma satisfação imediata às disposições empiristas - podemos observá-las, filmá-las, registrá-las, em suma, tocá-las com a mão -, escondem as estruturas que se concretizam nelas. Esse é um daqueles casos em que o visível, o que é dado imediatamente, esconde o invisível que o determina (BOURDIEU, 2004a, p. 153).

Logo, o espaço social aproxima os grupos de pessoas com características semelhantes, sendo suas relações visíveis o modo de vida comum. Entretanto, o que não se vê é o determinante para essas relações ou modo de agir. Seguindo o raciocínio, se a proximidade produz semelhança, a distância produz diferença. Um sujeito hierarquicamente superior a outro tende a se localizar distante no espaço social e geográfico, mesmo havendo a negação (puramente simbólica) dessa distância, pois ela serve, apenas, para conservar os privilégios. Bourdieu (2004a) chama de estratégia de condescendência a negação da distância que reforça a distância, tomando proveito tanto das proximidades como das distâncias. 
No espaço social situa-se o campo social, que é um espaço específico, determinado pelas relações de um poder (capital) específico. A posição de um agente dentro do campo depende do modo que detém o capital, bem como suas interações com agentes detentores de outras posições. "Nessa perspectiva, quanto mais capital, maior o poder de interferência das instituições [ou dos agentes] no interior do campo.” (BORGES, 2016, p. 214)

Imprescindível que, para o sujeito almejar o ingresso em determinado campo, deve identificar o tipo de capital em jogo ao tempo em que se relaciona com os demais integrantes para se posicionar de modo mais ou menos influente. Para isto, "Os novos [agentes] que entram têm de pagar um direito de entrada que consiste no reconhecimento do valor do jogo [...] e no conhecimento (prático) dos princípios de funcionamento do jogo." (BOURDIEU, 2003, p. 122) Logo, o ingresso no campo depende do conhecimento de suas regras, que exercerão influência no comportamento do sujeito.

Assim, um campo social deve apresentar os seguintes elementos: que a posição no campo depende também da trajetória do agente e de suas relações com outros campos, ou seja, quanto mais diferente de um campo, mais próximo de outro, sendo necessária a criação de regras de diferenciação para identificar o campo específico, a exemplo de leis, costumes e linguajar. Deve haver um capital específico, sendo este identificado dentro de outros três tipos de capital genérico, quais sejam: capital econômico, cultural e seus efeitos simbólicos (BOURDIEU, 2004a, p. 154). É possível que determinado capital auxilie na aquisição de outro tipo de capital, como o econômico que pode ser um recurso para a aquisição de capital cultural.

O campo funciona em termos de um mercado, em que se negocia um capital, que não se limita ao capital econômico, isto é, a realidade social não se limita ao fator econômico, apesar de sua relevância considerada pela abordagem bourdieusiana. Essa negociação consiste nas relações de forças que originam a estrutura do campo, envolvendo as espécies e a quantidade de capital envolvido. O campo possui relativa autonomia em detrimento de outros, dada a sua característica de se diferenciar dos demais para adquirir sua própria identidade, logo "A noção de campo está aí para designar esse espaço relativamente autônomo, esse microcosmo dotado de suas leis próprias." (BOURDIEU, 2004b, p. 20) e não é absoluta por se submeter a leis sociais em uma perspectiva do macrocosmos, havendo relação de troca mútua de valores entre os campos. 
Bourdieu $(1989 ; 2001 ; 2004 a)$ atribui destaque a um campo específico, que é o campo do poder, que é dado pelas relações de forças entre as mais diversas formas de capital, no qual os detentores do capital objetivam impor uma legítima dominação, isto é, posicionar seu capital como dominante. Os dominantes ao tempo que exercem a dominação, também são dominados pelos conflitos entre os diversos campos, pois a relação de dominação não é unilateral, mas, sim, é constituída de uma série de atitudes relacionais complexas. A dinâmica do campo produz o modo de agir de seus integrantes, isto por meio da disputa entre seus agentes, o que revela a ação interessada dentro do campo, mesmo que o interesse seja em outro campo. Assim, para Bourdieu (2004a), toda conduta tem um interesse que está envolvido nas regras do jogo do campo específico, conduzido por uma razão e o objetivo do pesquisador social é entender essa razão.

Bourdieu (2001) intenta, com a análise do campo, identificar a posição de determinado campo social com o campo do poder, a exemplo de se saber qual a influência do campo jurídico com os demais campos sociais, o que ele denomina de poder do direito. Identificar a estrutura relacional dos agentes integrantes do campo social e identificar o habitus adquirido por meio da internalização dos valores sociais e econômicos na trajetória dentro do campo. Por isso, a necessidade de se estudar o habitus, que passa a ser feito a seguir.

Outra categoria tratada é o habitus, sendo um conjunto de disposições geradoras de práticas ao tempo que é gerada pelas práticas e princípios. O termo habitus, utilizado por Bourdieu (2004a) não tem um significado uniforme, mas sim uma teia semântica, em que as disposições podem ser os valores da família, escola, classe social a qual está inserido, logo é formado pela experiência (práticas no decorrer da história) e originam as ações.

Nas palavras de Bourdieu (2004a, p. 158), habitus são "as estruturas mentais através das quais eles [os sujeitos] apreendem o mundo social, são em essência produto da interiorização das estruturas do mundo social." Percebe-se que o habitus é adquirido socialmente, não sendo predisposições inerentes ao ser humano. Com isso, são produtos e produtores sociais ao mesmo tempo. Como produtor social, o habitus age de modo que o agente pratique uma ação que julgue correto mesmo sem uma reflexão sobre o ato, o que tem por conseqüência um padrão comportamental dentro de um campo específico.

O habitus não se confunde com o inconsciente, ele está justamente a um meio termo entre o mecanicismo e a reflexão, é um senso comum, manifestando-se não apenas em atitudes físicas, mas também em juízo de valor acerca de determinada matéria posta, sendo 
um capital genérico internalizado por meio das experiências sociais. É uma “[...] espécie de sentido do jogo que não tem a necessidade de raciocinar para se orientar e se situar de maneira racional num espaço" (BOURDIEU, 1989, p. 62). É esse senso comum que se segue para produzir as práticas sociais ao tempo em que é estruturada pelas próprias experiências sociais.

Inda (2001, p. 29) divide o habitus enquanto produto em dois modos, quais sejam, primários e secundários. O habitus primário corresponde às disposições mais duradouras, antigas, primitivas e que, por sua vez, condicionam a internalização de novas disposições e cita o exemplo da família. O habitus secundário são aquelas disposições que se sobrepõem ao primário e reforçam sua eficácia. $\mathrm{O}$ autor evidencia que não há uma regra de superposição entre as disposições, já que o habitus é uma estrutura em constante construção, visto que as experiências que os agentes têm contato não cessam.

Essa estrutura de percepção da realidade social origina as representações sociais dos sujeitos, que variam de acordo com sua posição no campo e pela própria formatação dessa estrutura cognitiva, o que implica em classificações do tipo gosto musical que pode indicar o grau de erudição do sujeito ou o modo de se vestir que pode indicar se a pessoa é um executivo de grande empresa, por exemplo. E ao elegerem suas preferências, estão se enquadrando em suas classificações, por isso, “ [...] nada classifica mais uma pessoa do que suas classificações" (BOURDIEU, 2004a, p.159). Certamente, ao classificar, o agente vai eleger suas preferências e ai estará se autoclassificando e se enquadrando nos grupos que se identificam com as classificações.

O conjunto de disposições comuns de um grupo de pessoas é o que Bourdieu (2007a) denomina de habitus de classe, que são nada mais do que habitus individual que absorve e reflete as disposições do grupo a que está inserido. Assim, para se identificar uma classe social necessário avaliar o habitus de classe presente no grupo de pessoas que a integram. $\mathrm{O}$ habitus não provoca condutas desordenadas, pelo contrário, há uma sistematicidade das práticas em conformidade com os princípios internalizados, que é tão mais influente quanto for a sua durabilidade e capacidade de transferência de um campo a outro. Abaixo, a ideia de habitus de classe.

[...] habitus como sistema das disposições socialmente constituídas que, enquanto estruturas estruturadas e estruturantes, constituem o princípio gerador e unificador do conjunto das práticas e das ideologias características de um grupo de agentes. (BOURDIEU, 2007a, p. 191) 
As práticas sociais são o encontro do habitus com as determinações do campo em que o sujeito está inserido. Apesar da durabilidade, o habitus não é imutável, pelo contrário, está em constante mudança. Considerando que a prática surge com a interação entre os estímulos do campo social e habitus, logo, mesmo habitus exposto a diversos campos geram diferentes práticas sociais. Os efeitos do habitus permanecem mesmo após a cessação das disposições que o originaram, o que fortalece sua durabilidade.

Com o domínio de um determinado capital simbólico conseguido por meio de lutas passadas, os agentes intentam reproduzir um senso comum, pois é por meio deste que se consegue uma homogeneidade racional e comportamental e consequentemente uma sociedade mais coesa. Logo, tem-se o Poder Simbólico, que constrói a realidade por meio deste senso comum, muito embora nunca haja um senso de unanimidade em decorrência do conflito entre poderes simbólicos, e se garante legitimidade aos títulos que reforçam o capital simbólico em questão. Note que o poder simbólico age com uma violência encobertada, pois provoca uma sensação de conformismo e concordância no seio da sociedade, como segue abaixo.

O poder simbólico é um poder de construção da realidade que tende a estabelecer uma ordem gnoseológica: o sentido imediato do mundo (e, em particular, do mundo social) supõe aquilo a que Durkheim chama o conformismo lógico, quer dizer, uma concepção homogénea do tempo, do espaço, do número, da causa, que torna possível a concordância entre as inteligências. (BOURDIEU, 1989, p. 9)

Diante de um panorama de estabilidade social conquistado, ou seja, diante da concordância das inteligências do grupo, Bourdieu entende a possibilidade de rompimento do seguinte modo: "para mudar o mundo, é preciso mudar as maneiras de fazer o mundo, isto é, a visão de mundo e as operações práticas pelas quais os grupos são produzidos e reproduzidos." (2004a, p. 166). O poder simbólico é o mecanismo de criação de grupos, que é o mesmo de realizar mudanças e deve ser capaz de alterar os elementos objetivos e subjetivos do grupo.

O Poder Simbólico deve estar amparado em um capital simbólico, que é o prestígio adquirido suficiente para que haja um poder suficiente de disseminar e influenciar uma visão de mundo. Sem o capital simbólico não há força persuasiva nem prestígio suficiente ao convencimento das ideias que se pretende reproduzir visando a internalização dos agentes receptores. O poder simbólico será mais eficaz quanto mais próximo estiver da realidade, ou seja, uma teoria com alto grau de abstração terá poucas chances de formar um grupo. 
O poder simbólico é um poder de fazer coisas com palavras. É somente na medida em que é verdadeira, isto é, adequada às coisas, que a descrição faz as coisas. [...] um grupo - classe, sexo (gender), região, nação - só começa a existir enquanto tal, para os que fazem parte dele e para os outros, quando é distinguido, segundo um princípio qualquer, dos outros grupos, isto é, através do conhecimento e do reconhecimento. (BOURDIEU, 2004a, p. $166 / 167)$

Assim, o poder simbólico deve estar próximo da realidade porque ele cria um grupo revelando este grupo, distinguindo-o dos demais. Sem essa atribuição, inexistirá o grupo com identificação e organização própria.

\section{3 - As disputas no campo jurídico como geradoras de práticas sociais}

Conforme dito anteriormente, o campo é um espaço social em que há disputas envolvendo um capital específico. Os agentes do campo se relacionam operando alianças, cooperações ou por meio de conflitos e concorrências. No caso do campo jurídico, as relações giram em torno do capital jurídico e de seus efeitos simbólicos, em que os conflitos e alianças visam o monopólio de se ditar qual o direito aplicável aos casos. Corroborando o entendimento exposto, segue posicionamento abaixo.

Bourdieu (1986) define el campo jurídico como um "campo de batalha", en donde se lucha por el monopolio que da a los agentes la potestad decir decidir - qué es derecho y qué no es. Esta lucha se desarolla entre agentes especializados que pretendem acumular la mayor cantidad de capital jurídico. (NAVARRO; DURÁN, 2012, p. 48)

Quanto maior a quantidade de capital acumulado, maior será a influência dentro do campo e o reconhecimento do agente. Percebe-se que o campo é constituído por disputas de interesses, que vai fazendo surgir as regras de comportamento específicas para o campo, em que os agentes deverão se adequar com maior ou menor intensidade, o que influenciará em seu desempenho na acumulação de capital.

O campo jurídico é uma ilusão social, cujo objetivo final é ocultar, por formas jurídicas, as relações de dominação, tendo como estratégia a ideia de universalização, neutralidade e autonomia de seus preceitos, disciplinando práticas sociais de seus membros que internalizam o discurso jurídico como válido. Os membros do campo pretendem manter 
ou modificar sua posição e a atividade científica tem o objetivo de produzir conhecimento que camuflem a percepção das lutas internas.

En este sentido, la neutralidad científica de la reflexión contribuye al enmascaramiento de la violencia implícita en el discurso jurídico que se expresa a través de la desaparición metódica de todo signo exterior de violência. (NAVARRO; DURÁN, 2012, p. 50)

A violência tratada acima é a imposição do capital de uma pessoa ou grupo sobre outros agentes, tendo o discurso jurídico uma dupla função, que é a operacionalização da violência e a sua ocultação a fim de conter possíveis movimentos de resistência. É esse jogo de disputa que delimita o campo específico. Dentro do campo, há agentes profissionais, que têm consciência das regras, e agentes que não possuem noção das disputas existentes, apesar de integrá-lo e buscar a aquisição do capital envolvido.

Nesse contexto, o direito pode ser visto sob dois pontos de vista, o internalista e o externalista. $\mathrm{O}$ primeiro corresponde à visão pura do direito, entendida no sentido de que o campo jurídico juntamente com seu corpo judicial é independente de influências externas. $\mathrm{O}$ segundo defende a ideia de que o direito é um mero instrumento a serviço de um grupo específico e que detém o poder social. O que propõe Pierre Bourdieu (2001) é que o campo jurídico possui autonomia em relação ao meio externo e que cria a violência simbólica (autoridade) por meio do monopólio estatal, o que não significa afirmar que o referido campo não se submete em nenhum grau à influência de outros campos dentro do direito. Entretanto, sua autoridade possui uma significativa autonomia ao ponto de influenciar outros campos. Conforme entendimento de Bourdieu:

El campo jurídico es el lugar de una concurrencia por el monopolio del derecho de decir el derecho, esto es, la buena distribución (nomos) o el buen orden en el que se enfrentán agentes investidos de una competencia inseparablemente social y técnica, que consiste esencialmente en la capacidad socialmente reconocida de interpretar (de manera más o menos libre o autorizada) un corpus de textos que consagran la visión legítima, recta, del mundo social. Sólo em estos términos se puede dar razón, ya de la autonomía relativa del derecho, ya del efecto propiamente simbólico de desconocimiento que resulta de la ilusión de su autonomía absoluta en relación a las demandas externas (BOURDIEU, 2001, p. 169) . 
Logo, a autonomia do direito reside no fato de que seus agentes são detentores do monopólio de identificar o que é correto no mundo social ao interpretar seu corpo de textos. Essa autonomia é relativa, já que ao tempo que influencia, também, é influenciada por outros campos. Bourdieu (2001) aponta como motivos da defesa da autonomia absoluta do direito o desconhecimento e ilusão. Há, nos internalistas, uma supervalorização da autonomia do direito, criando a ilusão de um poder em si mesmo. A comunicação entre o direito e outros campos é reconhecida quando o autor põe como inseparável a competência social e técnica dos agentes do direito. A técnica pode ser exemplificada como ato de profissionais em interpretar os textos jurídicos, que representa uma luta para apropriação da força simbólica do direito.

O campo, que é uma construção social, é produto de seus agentes. Por meio da atuação dos profissionais e não profissionais cria o campo com suas regras e símbolos bem como opera as transformações. Essas regras servem para proporcionar coesão entre os agentes, não sendo as mesmas regras das diversas áreas do direito. A primeira corresponde a códigos que impõem comportamentos revestidos de homogeneidade, implicando em maior identidade entre os agentes do campo jurídico. Já a segunda é o próprio instrumento adquirido pelos agentes do campo jurídico, que representa a separação entre a classe dominante (que detém o monopólio de dizer o direito) e dominada (que se submete ao direito do dominante).

Dentro de cada campo, há uma linguagem específica, que é um tipo de capital em que os profissionais devem manejar. Um advogado quanto mais domina a linguagem jurídica e os recursos de poder inerentes ao campo, mais chance terá de alcançar as pretensões almejadas pelos seus constituintes e maior destaque terá dentro do campo jurídico. O campo é dinâmico, ou seja, há uma série de relações de força internas ocorrendo, que o origina e o altera. Entretanto, alguns agentes visam a manutenção das posições, enquanto outros visam a modificação, sendo os primeiros os dominantes e os segundos os dominados. A abordagem bourdieusiana atribui o termo teoria da reprodução aos mecanismos de conservação das relações dominantes e dominados, isto é, há a promoção de regras em que todos devem observar para se encaixar no campo. A internalização dessas regras pelos dominados, provocam uma aceitação passiva das vantagens do grupo dominante, são os dominados assimilando as regras dos dominantes.

No campo acadêmico, a produção dos textos jurídicos, a exemplo das dissertações e teses de pós-graduação, reflete a posição dentro do espaço social em que o autor se encontra 
ou ao menos incorporou o discurso de uma classe específica a que pretende ser integrado. Com isso, quanto mais grupos com interesses divergentes existirem, maior será a diversificação na confecção e interpretação dos textos. A produção acadêmica é um mecanismo em que há fortes lutas simbólicas entre os agentes que integram o campo social e em especial sob a análise em curso o campo jurídico.

Bourdieu (1989, p. 213) dispõe que "como no texto religioso, filosófico ou literário, no texto jurídico estão em jogo lutas, pois a leitura é uma maneira de apropriação da força simbólica que nele se encontra em estado potencial." A latência do texto é interrompida pelas ações práticas em que o leitor irá empreender em busca da conquista de posições dentro do espaço. É nessa leitura com a orientação da interpretação em que reside a violência simbólica, pois muitos agentes tomam para si valores que vão de encontro aos seus próprios interesses, que em regra se dá ao leitor em posição desfavorecida.

A produção acadêmica, especialmente em direitos humanos, tem a finalidade de demonstrar aos leitores essa relação de dominação e de luta existente, que é corriqueiramente negada pelos agentes detentores de posições privilegiadas. Dissertações e teses em direitos humanos que visam reproduzir relações de desigualdade social estão a serviço do fortalecimento da estruturação de habitus produtor de senso comum e justificador da realidade, havendo, assim, desvio de finalidade de uma educação que tem em sua essência descortinar as fantasias da neutralidade, universalidade e racionalidade do direito e apontar sua natureza impositiva e parcial em favor de classes dominantes.

O campo da educação é um espaço eficaz para a prática da teoria da reprodução, como dito a seguir.

La educación forma nuevas personas con base em los elementos previamente establecidos de la sociedad, para inculcarles la adhesión al orden social que el campo legitima. Si se hace uma reflexión de um orden social como el jurídico, se entiende que estos campos van a ser por excelencia, los garantes o los estabilizadores más grandes en la lógica de cualquier outro campo. (NAVARRO; DURÁN, 2012, p. 52)

Como a educação garante a reprodução social e a estabilização dos valores da classe dominante e legitimação do campo (BOURDIEU; PASSERON, 1992), em especial o campo jurídico, prolonga esses efeitos para além de seus limites, influenciando, de modo eficaz, vários outros campos. É da essência do direito provocar uma estabilidade social, ou seja, 
conter possíveis discórdias que alterem a lógica em curso dos campos. Desse modo, a legitimidade social em cada campo se dá por meio da ação reguladora do direito. Nota-se que o direito por se constituir como um campo, é socialmente construído ao tempo que participa da construção de outros campos, na medida em que regula as posições de seus agentes por meio da edição de regras.

O habitus dentro de um campo representa as normas e condutas internalizadas pelos agentes, que o repetem de modo espontâneo e formam uma estrutura mental que dão amparo aos juízos de valor do sujeito. O habitus jurídico consiste nas disposições que o agente do campo jurídico possui em aceitar ou negar a legitimidade do direito. "Entonces el habitus jurídico es la forma de asimilar lo que es el derecho y la forma de poner em práctica esos conocimientos asimilados, porque todos los hábitos se reflejan en la acción práctica" (NAVARRO, DURÁN, 2012, p. 54). Como todo habitus implica em uma ação prática, o jurídico também segue essa regra e, em especial, para o sujeito discernir o que é juridicamente aceitável ou não. $\mathrm{O}$ direito essencialmente tem o fim de impingir na sociedade a aceitação da realidade, sendo sua negação um desvio de padrão aceitável.

Sobre a categoria capital, Bourdieu (2004a) aponta três tipos como principais, que são o econômico, social e cultural. O capital econômico é o poder decorrente dos recursos financeiros, o capital social são as influências oriundas de agentes que integram organizações. O capital cultural são as disposições adquiridas nos processos de socialização, podendo ser dividida em educacional, quando internalizados conhecimentos, e capital simbólico, que corresponde a juízos de valor sobre a moral e gosto artístico, por exemplo.

Todo campo tem em jogo a disputa de um capital específico, no caso do direito é o capital jurídico que é alvo dos conflitos dos agentes do campo jurídico. O capital jurídico tem o poder de legitimar discursos dominantes, servindo, dessa forma, para regular e legitimar o aparato estatal existente. Tais aspectos são conseguidos não por acaso, mas, se utilizando de toda a estrutura jurídica, como explicitado a seguir.

En el campo de lo jurídico el capital está integrado por toda la simbologia por el lenguaje codificado, que desde el punto de vista lingústico y sociológico no es outra cosa que un lenguaje eminentemente simbólico, codificado en ritos y prácticas y en los espacios donde se despliegan los discursos de la juridicidad como los estrados judiciales, las faculdades de derecho, las oficinas públicas y privadas consultoras donde ejercen los juristas. (NAVARRO; DURÁN, 2012, p. 55) 
O capital jurídico simbólico atua por meio de suas instituições, a exemplo de órgãos públicos e faculdades de direito, que orientam o comportamento dos agentes por meio da difusão ou reprodução de símbolos cabíveis, impingindo, no coletivo, as representações sociais do campo. É um discurso que falsamente se esconde atrás da neutralidade, universalidade e desinteresse político. Bourdieu (2001) expõe que esse discurso não é uma simples máscara ideológica, mas, sim, o próprio funcionamento do campo jurídico, que garante sua autonomia real de pensamentos e práticas.

Todo discurso é político, interessado e com posições bem definidas. Entretanto, o discurso jurídico encontra sua força de convencimento na negação dos interesses e na naturalização dos valores que se pretendem difundir, representando o reconhecimento unânime da força dos textos jurídicos. Esse discurso, também, pretende empoderar os detentores do direito, ou seja, legitimar os agentes (autoridades) que detêm o monopólio de dizer o direito aplicável à sociedade.

O direito faz uso da estratégia da polarização em pontos antagônicos que a sociologia tradicional se detém e abordado em ponto anterior. Bourdieu relata a constante batalha simbólica por meio da interpretação dos textos jurídicos, conforme disposto a seguir.

Las distintas categorias de interprétes autorizados tienden siempre a distribuirse entre dos pólos extremos: por un lado, la interpretación orientada hacia la elaboración puramente teórica de la doctrina, monopolio de profesores que están encargados de enseñar las reglas en vigor bajo um forma normalizada y formalizada; por otro lado, la interpretación orientada hacia la evaluación práctica de un caso particular, patrimonio de los magistrados que llevan a cabo los actos de jurisprudencia y que por ese camino pueden, alguns de ellos, contribuir también a la construcción jurídica. (BOURDIEU, 2001, p. 175/176)

Percebe-se uma divisão em dois grupos de profissionais do campo jurídico. O primeiro dos professores que objetivam a construção doutrinária e, por isso, inserida no campo teórico. O segundo a aplicação das regras a casos concretos, assinalado como atividade prática de competência dos magistrados, mas acrescentamos nesse rol os advogados e promotores, que apesar de não praticarem atos de decisões processuais, atuam de modo a interferir em litígios concretos e influenciar as decisões dos magistrados.

Nessa luta simbólica entre magistrados e professores, o que terá mais influência dentro do espaço social e, por isso, detentor de maior significância na construção do campo jurídico, dependerá da ordem social a qual está inserida. As escolas francesa e alemã colocam em uma 
posição hierarquicamente mais elevada a atividade doutrinária e, por isso, a atividade dos professores tem maior poder de influência, inclusive ocupando cargos de maior importância. Já a escola anglo-americana põe a atividade prática em destaque, sendo a jurisprudência a construtora do direito, pondo o juiz em posições relevantes na sociedade.

Tem-se em debate dois tipos de capital jurídico que, na perspectiva de Bourdieu (2001) apesar de serem antagônicas, elas se complementam, isto é, não são excludentes. A construção teórica é relevante para o desenvolvimento do direito e uma fundamentação consistente das ideias, mas que não pode se afastar do mundo prático, do contato com a realidade social e a sensibilidade de cada caso concreto. A construção doutrinária facilita a padronização de regras e uma maior previsibilidade comportamental dos sujeitos, mas que muitas vezes se afastam das condutas dos agentes sociais. No entanto, a ampliação da influência jurisprudencial sem um balizamento teórico tende em reforçar a arbitrariedade de decisões dos magistrados. Nesse conflito de capital se constrói o campo jurídico com suas tradições e influências na ordem social.

A complementaridade entre atividade teórica e prática é inafastável, pois os juizes não são meros adequadores do caso concreto à norma aplicável, eles “[...] se inspiran en una lógica y en unos valores muy próximos a los de los textos sometidos a su interpretación, cumplen una verdadera función de invención" (BOURDIEU, 2001, p. 183). Portanto, o juiz está atrelado a uma norma. Entretanto possui autonomia para julgar de acordo com suas convicções, sendo influenciado pela leitura social de seu habitus. Isso significar dizer, que a mesma situação submetida a juízes com habitus diversos, teremos resultados distintos, apesar da inevitável aproximação do habitus de ambos em decorrência do capital institucional existente, quando for o caso.

As atividades acima discutidas se submetem ao ingresso dos agentes no mundo jurídico. Nada serve à construção teórica e prática dos juristas, se a sociedade não reconhece o campo jurídico como mecanismo de solução dos conflitos. Esse reconhecimento se dá com a aceitação da lei fundamental que rege o campo, nele incluso os agentes técnicos que dominam a linguagem jurídica e os não técnicos e que delegam a solução de seus conflitos, ou seja, abre-se mão de se buscar a satisfação dos interesses contraditados por meios próprios. Não é qualquer interesse que é abordado pelo espaço jurídico, mas aqueles previstos pelo direito. É o que se denomina de fato jurídico, que são aqueles reconhecidos pelas autoridades produtoras do direito. 
Para Bourdieu (2001, p. 191), o fato jurídico é resultado da construção jurídica. Nessa ótica, o direito é que produz os fatos relevantes que serão objetos de sua apreciação. Entretanto, tem-se que levar em consideração que o direito existe na medida em que existe o fato jurídico. O fato não jurídico compreende outros campos que não o jurídico, mas pode comprimir uma violência simbólica ou física para ser reconhecida como fato jurídico. Assim, o fato também é produtor do direito. Entendimento contrário implica em reconhecer exclusividade da construção jurídica às autoridades e mitigar forças extrajurídicas, o que só fortalece as classes dominantes. É com o revestimento jurídico dos fatos, em princípio não jurídicos, que se logra êxito em angariar mais adeptos ao campo do direito e manter o controle social por intermédio do poder simbólico.

Esse entendimento não afasta o monopólio estatal do direito, já que, institucionalmente, o reconhecimento do que vem a ser fato jurídico é ato exclusivo do Estado. O que foi discorrido é sobre a luta da construção do campo jurídico e a estratégia dominante em conceder reconhecimento jurídico em momentos oportunos na tentativa de manter-se em posição privilegiada dentro do espaço social, dada a força de influenciar a ordem social, que possui o campo jurídico.

É certo que a função primordial do direito é a manutenção da ordem social existente, isto por meio da reprodução de sua própria estrutura, entretanto pode haver um efeito contrário e o direito legitimar novas relações jurídicas, ou seja, legitimar uma nova ordem. Neste sentido, expõe abaixo.

La función de mantenimiento del orden simbólico que el campo jurídico contribuye a asegurar es, como la función de reproducción del campo jurídico mismo [...] y que incluso pueden inspirarse en intenciones opuestas, como los intentos subversivos de las vanguardias que, en definitiva, contribuyen a determinar la adaptación del derecho y del campo jurídico al nuevo estado de las relaciones sociales y a asegurar así la legitimación de la forma establecida de esas relaciones. (BOURDIEU, 2001, p. 223)

O estabelecimento de uma nova ordem não se dá por intermédio exclusivo do campo jurídico, mas, sim, com fortes influências de diversos outros campos como o artístico, científico e político. Com isso, no campo jurídico, existe uma constante luta simbólica, em que os detentores de posições privilegiadas visam a manutenção da realidade posta, sendo a ocupação dessas posições em sintonia com a dominação do poder político. 


\section{4 - Considerações Finais}

A compreensão das práticas sociais e o direito a partir de Pierre Bourdieu passam necessariamente pelo entendimento das categorias campo, habitus e capital. Conforme discorrido no presente texto, campo é o espaço social que se busca um determinado capital, este que é um poder de influenciar as relações sociais e o habitus são as disposições mentais que formam o juízo de valor das pessoais sobre a realidade que os circundam. A energia criadora do movimento destes elementos origina-se em pressupostos ocultos, ordenadores das condutas dos sujeitos e que é objeto da corrente reflexão.

$\mathrm{Na}$ sequência das ideias, reconhece-se a complementaridade entre as estruturas objetivistas que orientam a prática social (premissa estruturalista) e a origem das estruturas psíquicas que condicionam e geram comportamentos (premissa construtivista), categorias tradicionalmente vistas como oposições, para reconhecer a prática social enquanto resultado não de apenas um dado unilateral, mas sim da conjugação dos elementos campo, capital e habitus.

A partir dessa complexidade de interações, denota-se que há proximidade de pessoas com atributos semelhantes em um campo, identificando a maneira de vida comum e perceptível na realidade manifesta, todavia o que não se vê é o determinante para esses modos de agir. A mesma lógica de aproximação é o do afastamento entre os partícipes dos espaços, isto é, a força que se pretende inclusiva também é promotora de exclusão, sendo denominada de estratégia de condescendência a negação desta conjuntura, implicadora de reforço das desigualdades sociais.

É típico na dinâmica de um campo as disputas entre seus agentes, cujo objetivo é assimilar o capital almejado e assumir posições mais influentes, por isso, comportam-se em conformidade com as regras de funcionamento do espaço em jogo, ou seja, as condutas dos agentes se dão em função de uma razão. Deste modo, as práticas sociais surgem da interação entre os estímulos do campo social e o habitus, consistindo, o êxito do agente, no domínio de um determinado capital simbólico, que a partir de então se busca reproduzir um senso comum que o mantenha na posição alcançada, garantindo uma homogeneidade racional e comportamental e, por conseguinte, uma sociedade mais coesa.

Nesse contexto, tem-se o poder simbólico, instituidor da realidade por meio do senso comum, apesar de nunca ser obtido um senso de unanimidade em decorrência das disputas do campo, garantidor de legitimidade dos signos que reforçam o capital simbólico em questão. 
Portanto, o poder simbólico atua com violência camuflada, haja vista provocar sensação de conformismo e concordância pela sociedade, comumente comportando-se em favor de interesses dos detentores do poder simbólico como fossem os seus.

No campo jurídico, as interações se dão visando o capital jurídico e seus efeitos simbólicos, isto é, os conflitos e alianças dos agentes tem por escopo o monopólio de se ditar qual o direito a ser seguido pela sociedade. Considerando que os detentores do capital em questão reproduzem signos que o mantenham nas posições mais influentes, o direito oculta relações de dominação por meio de suas formas, conformando práticas sociais sob o argumento da neutralidade e universalidade dos regramentos.

A complexidade do movimento entre campo, capital e habitus na produção de práticas sociais implica em reconhecer o direito tanto como produtor como produto comportamental, ao tempo que as regras do jogo consideram tanto a adesão aos símbolos prevalentes do campo como sua modificação, significa afirmar que a dinâmica da construção do habitus é permanente, representando a tensão conservadora e criadora de senso comum em favor dos interesses dos agentes.

\section{Referências}

BORGES, Maria Creusa de Araújo. O Supremo Tribunal Federal e as ações afirmativas na universidade: As audiências públicas e a análise bourdieusiana do campo jurídico-social. In: (orgs) Conpedi; Udelar; Unisinos; URI; UFSM; Univali; UPF; FURG. Sociologia, antropologia e cultura jurídicas. Florianópolis/Brasil, Montevidéu/Uruguai: CONPEDI, $2016 . \quad$ Disponível em: <https://www.conpedi.org.br/publicacoes/9105o6b2/360qtmi1/0X3QC0KNI60L75Eu.pdf> Acesso em: 10. dez. 2020.

BOURDIEU, Pierre. A distinção: crítica social do julgamento. Tradução: Daniela Kern e Guilherme J. F. Teixeira. São Paulo: Edusp; Porto Alegre, RS: Zouk, 2007a.

BOURDIEU, Pierre. A escola conservadora. In: (orgs) NOGUEIRA, Maria Alice; CATANI, Afrânio. Escritos de educação. Petrópolis/RJ: Vozes, $2007 \mathrm{~b}$.

BOURDIEU, Pierre. Capital simbólico e classes sociais. Tradução: Fernando Pinheiro. Revista Novos Estudos. N. 96. 2013. Disponível em: < http://www.scielo.br/pdf/nec/n96/a08n96.pdf>. Acesso em: 12. jan. 2021

BOURDIEU, Pierre. Coisas ditas. Tradução: Cássia R. da Silveira e Denise Moreno Pegorim. São Paulo: Brasiliense, 2004a. 
BOURDIEU, Pierre. O Poder simbólico. Tradução: Fernando Tomaz. Rio de Janeiro: Editora Bertrand Brasil S. A., 1989.

BOURDIEU, Pierre. Os três estados do capital cultural. In: (orgs) NOGUEIRA, Maria Alice; CATANI, Afrânio. Escritos de educação. Petrópolis/RJ: Vozes, 2007c.

BOURDIEU, Pierre. Os usos sociais da ciência: por uma sociologia clínica do campo científico. Tradução: Denice Barbara Catani. São Paulo: Editora UNESP, 2004b.

BOURDIEU, Pierre. Para uma sociologia da ciência. Tradução: Pedro Elói Duarte. Lisboa: Edições 70, 2004c.

BOURDIEU, Pierre. Poder, derecho y clases sociales. Traducción: Maria José Bernuz Beneitez. Andrés Garcia Inda. Maria José González Ordovás. Daniel Oliver Lalana. 2a Edição. Bilbao: Editorial Desclée de Brouwer S. A., 2001.

BOURDIEU, Pierre. Questões de sociologia. Tradução: Miguel Serras Pereira. Lisboa: Fim de Século - Edições, Sociedade Unipessoal, 2003.

BOURDIEU, Pierre; PASSERON, Jean-Claude. A reprodução: elementos para uma teoria do sistema de ensino. Tradução: Reynaldo Barão. $3^{\text {a }}$ Ed. Rio de Janeiro/RJ: Livraria Francisco Alves Editora S.A., 1992.

INDA, Andrés Garcia. "Introducción - La razón Del derecho: entre habitus y campo." BOURDIEU, Pierre. Poder, derecho y clases sociales. Traducción: Maria José Bernuz Beneitez. Andrés Garcia Inda. Maria José González Ordovás. Daniel Oliver Lalana. 2a Edição. Bilbao: Editorial Desclée de Brouwer S. A., 2001.

INDA, Andrés Garcia. La regla em La teoria de La práctica de Pierre Bourdieu. Revista Acciones e Investigaciones Sociales. V. 3. 1995. Disponível em: < http://www.unizar.es/centros/eues/html/archivos/temporales/03_AIS/AIS_03_14.pdf>.

Acesso em: 05. fev. 2021.

NAVARRO, Mónica Patricia Fortich; DURÁN, Álvaro Moreno. Elementos de la teoría de los Campos de Pierre Bourdieu para una aproximación al derecho em América Latina: consideraciones previas. Revista Verba Iuris. 2012. Disponível em: $<$ http://www.unilibre.edu.co/verbaiuris/27/elementos-de-la-teoria-de-los-campos-de-pierrebourdieu-para-una-aproximacion-al-derecho-en-america-latina-consideraciones-previas.pdf> Acesso em: 12. fev. 2021. 